\title{
Analisis Daya Tampung Beban Pencemaran Air Sungai Asam Kota Jambi
}

\author{
Ridho Renaldi ${ }^{1}$, Marhadi ${ }^{2}$, dan Anggrika Riyanti ${ }^{3}$ \\ Program Studi Teknik Lingkungan, Fakultas Teknik, Universitas Batanghari \\ Jalan Slamet Riyadi, Kota Jambi \\ e-mail: ridhorenaldi.50@gmail.com
}

\begin{abstract}
The Asam River is one of the rivers that crosses the sub-districts, including Kota Baru, Jelutung and Pasar Jambi. Asam River is located in Jambi City with a length of $10.68 \mathrm{~km}$, and a watershed area of 2,930 Ha. The Asam River is generally polluted by waste originating from activities, office areas, hotels, trade centers, prominent figures and residential areas. To determine the quality of acid river water, it is necessary to analyze the load carrying capacity of water pollution. Methods that can be used to analyze the load carrying capacity of water pollution include the Mass Balance method and the Streeter-Phelps method. Based on the results of the calculation of the carrying capacity of the river pollution load using the mass balance method on the parameters, pH, TSS, BOD and COD. The Asam River which cannot accommodate the pollution load is found in the TSS parameter of $-110.129 \mathrm{mg} / \mathrm{l}$ with a quality standard of $30 \mathrm{mg} / \mathrm{l}$ according to the Ministry of Environment and Forestry Number P.68 of 2016 concerning domestic waste quality standards, while for the parameters pH, BOD, and COD still below the domestic waste quality standard. The results of the calculation of the carrying capacity of the pollution load using the streeter-phelps method show that at 4 sampling points the BOD concentration can still accommodate the pollution load in the river which does not exceed the quality standard. the effect of DO concentration on AP1 Upstream to AP4 Downstream is still available in sufficient amount of DO.
\end{abstract}

Keywords: capacity, pollution load, River water

\section{Pendahuluan}

Kuantitas air umumnya sangat dipengaruhi oleh lingkungan fisik seperti curah hujan, topografi dan jenis batuan. Menurunnya kualitas air disebabkan oleh kandungan sedimen yang bersumber dari erosi atau kandungan bahanbahan senyawa yang berasal dari pembuangan kegiatan pemukiman, industri dan pertanian akan berdampak pada masuknya bahan pencemaran ke aliran sungai (Tanjung, Maury and Suwito, 2016) Suatu dampak buangan akan mengalami perubahan kondisi kualitas air. (Dyah, Sasongko and Sudarno, 2012).

Sungai Asam adalah salah satu sungai yang melintasi kecamatan antara lain Kota Baru, Jelutung dan Pasar Jambi. Sungai Asam terletak di Kota Jambi dengan panjang 10,68 $\mathrm{km}$, dan luas DAS 2.930 Ha. Sungai Asam umumnya tercemar oleh limbah yang berasal dari kegiatan-kegiatan, kawasan perkantoran, hotel, kawasan pusat perdagangan, tokoh dan permukiman padat penduduk yaitu dengan banyaknya permukiman warga di sekitar Sungai Asam yang aliran drainasenya masuk ke sungai, maka semakin meningkat pula limbah yang dihasilkan. Berdasarkan hasil analisa kualitas air Sungai Asam dari Dinas Lingkungan Hidup Kota Jambi bulan Agustus Tahun 2020 menunjukan bagian hulu Jalan Lingkar Selatan Kenali Asam Bawah, untuk parameter DO sebesar $5,48 \mathrm{mg} / \mathrm{l}$, BOD sebesar 1,4 mg/l, COD sebesar 22,2 mg/l, TSS sebesar 65,3, mg/l, dan pH sebesar 6,96 mg/l, sedangkan bagian hilir Kelurahan Orang Kayo Hitam Kecamatan Pasar Kota Jambi, untuk parameter DO sebesar 2,50 mg/l, BOD sebesar 16,87 mg/l, COD sebesar 45,3 mg/l, TSS sebesar 40, $\mathrm{mg} / \mathrm{l}$, dan $\mathrm{pH}$ sebesar $6,80 \mathrm{mg} / \mathrm{l}$. hasil data Dinas Lingkungan Hidup Kota Jambi menunjukan dari hulu sampai hilir parameter semangkin tinggi terdapat pada bagian hilir yang seharusnya sesuai baku mutu Peraturan Pemerintah No 82 Tahun 2001, (Dinas L.H, 2020).

Untuk mengetahui kualitas air sungai asam, maka diperlukan analisis daya tampung beban pencemaran air. Metode yang dapat digunakan untuk menganalisis daya tampung beban pencemaran air antara lain adalah metode Neraca Massa dan Metode Streeter-Phelps. Metode ini salah satu dari metode resmi yang ditetapkan oleh KepMen LH No.110 tahun 2003. Namun metode ini memiliki kelebihan dan kekurangan. Kelebihan dari pada metode Neraca Massa ini adalah formulasinya cukup mudah, sedangkan kekurangannya adalah kurang teliti. Kelebihan dari Metode Streeter-Phelps ketelitian baik, sedangkan kekurangannya formulasi rumit.

Dengan demikian penelitian dilakukan untuk mengetahui kualitas air Sungai Asam Kota Jambi, serta menganalisis daya tampung beban pencemaran Sungai Asam Kota jambi, melalui penerapan model Neraca Massa dan Streeter-Phelps.

\section{Metode Penelitian}

Penelitian ini merupakan penelitian deskriptif dengan menggabungkan metode pendekatan kuantitatif, Pendekatan kuantitatif dalam penelitian ini digunakan untuk menggambarkan Daya Tampung Beban Pencemar pada Sungai Asam dan digunakan untuk menetapkan kebijakan pengendalian pencemaran air.

\subsection{Lokasi dan Waktu Penelitian}

Penelitian ini dilakukan di Wilayah Sungai Asam Kota Jambi, Lokasi penelitian dibagi menjadi 4 titik lokasi (air permukaan) yaitu AP1 hulu, AP2 tengah, AP3 tengah dan AP4 hilir Kegiatan penelitian dilakukan pada tanggal 19 Januari 2021.

\subsection{Bahan dan Alat Penelitian}

Alat yang digunakan untuk melaksanakan penelitian ini antara lain :

1. Alat pengambilan sampel air (water sampler)

2. Meteran

3. Current meter

4. GPS

5. Stop watch

6. Peta

7. Kamera dan

8. Dokumentasi 
Bahan yang digunakan untuk melaksanakan penelitian ini adalah sampel air Sungai Asam di setiap titik.

\subsection{Penentuan Titik Sampling}

penentuan titik sampling dilihat dari kondisi aktivitas yang ada di lingkungan sepanjang sungai asam (poin source dan non poin source). Pemilihan beberapa lokasi sampel ini bertujuan untuk melihat perbandingan tingkat pencemaran yang terjadi di sepanjang aliran sungai asam. dan sesuai (SNI 03-7016-2004) yang telah mengatur dasar-dasar yang harus dipertimbangkan antara lain:

1. Kualitas air sebelum adanya pengaruh kegiatan manusia yaitu pada lokasi hulu sungai untuk mengetahui kualitas air secara alamiah

2. Pengaruh kegiatan manusia terhadap kualitas air dan pengaruhnya untuk pemanfaatan tertentu

3. Sumber-sumber pencemaran yang dapat memasukkan zatzat yang berbahaya kedalam sumber air.

\subsection{Prosedur Pengambilan Sampling}

Pengambilan contoh uji untuk analisa parameter kualitas air dibedakan menjadi 2 (dua) yaitu parameter lapangan dan parameter laboratorium. Pengambilan contoh uji untuk pengukuran $\mathrm{pH}$ dan $\mathrm{DO}$ secara langsung dilapangan masing-masing menggunakan beaker glass dan botol winkler $125 \mathrm{~mL}$. Sedangkan pengambilan contoh uji untuk pengukuran laboratorium menggunakan botol contoh uji. Pengambilan sampel air permukaan mengacu pada (SNI 6989.57:2008) :

1. Menyiapkan wadah sampel

2. Membilas wadah sampel dengan air suling

3. Menyiapkan alat pengambil sampel sesuai keadaan sumber air

4. Membilas alat pengambil sampel

5. Mengambil sampel sesuai titik sampling dan memasukkannya ke wadah sampel sesuai peruntukan analisis

6. Hasil pengujian parameter lapangan dicatat didalam buku

7. Memberi label pada wadah sampel

8. Melakukan pengawetan sampel sesuai peruntukan uji

9. Mengamankan sampel dan wadah

10. Mencatat nama sumber air, tanggal dan jam pengambilan, keadaan cuaca, bahan pengawet yang ditambahkan

Pengisian contoh uji ke dalam botol harus melalui dinding dan memenuhi botol, dan terhindar dari terjadinya turbulensi dan gelembung udara. Setelah itu, pengawetan contoh uji pada cool box berpendingin $\pm 4^{0} \mathrm{C}$. kualitas air di lapangan (DO, Temperatur, dan $\mathrm{pH}$ ) dan di laboratorium Dinas Lingkungan Hidup Provinsi Jambi (COD, BOD, dan TSS).

Tabel 1 Pembagian titik sampling dan sumber pencemaran Sungai Asam

\begin{tabular}{cccccc}
\hline No & Titik & Panjang & Garis Lintang & Garis Bujur & Rona Lingkungan \\
\hline 1 & $\begin{array}{c}\text { AP1 } \\
\text { (Hulu })\end{array}$ & $1.14 \mathrm{~km}$ & LS: $01^{\circ} 40^{\prime} .248^{\prime}$, & BT: $103^{\circ} 36^{\prime} .250^{\prime}$, & Permukiman warga/perumahan \\
2 & $\begin{array}{c}\text { AP2 } \\
\text { Tengah }\end{array}$ & $3.10 \mathrm{~km}$ & LS: $01^{\circ} 38^{\prime} .236^{\prime}$, & BT: $103^{\circ} 36^{\prime} .115^{\prime}$, & $\begin{array}{c}\text { Permukiman warga, perdagangan, tokoh, } \\
\text { daerah perkantoran, rumah makan } \\
\text { Permukiman warga,pasar, perdagangan, pusat } \\
\text { tokoh daerah perkantoran, rumah makan dan } \\
\text { variasi/bengkel mobil } \\
\text { AP3 }\end{array}$ \\
$\begin{array}{c}\text { Tengah } \\
\text { AP4 }\end{array}$ & $3.10 \mathrm{~km}$ & LS: $01^{\circ} 36^{\prime} .925^{\prime}$, & BT: $103^{\circ} 36^{\prime} .633^{\prime}$, & $\begin{array}{c}\text { Pemukiman warga, rumah makan pusat } \\
\text { perdagangan, bengkel mobil,pusat tokoh, pusat } \\
\text { pasar, ternak kambing dan hotel }\end{array}$ \\
\hline
\end{tabular}

Dari tabel di atas penentuan titik sampling dalam penelitian ini ditentukan 4 titik lokasi pengambilan sampling, dimana pengambilan sampling titik hulu (AP1) dan hilir (AP4) mengikuti lokasi dari data sekunder DLH Kota Jambi, sedangkan titik tengah (AP2) dan (AP3) penentuan titik tersebut menyesuaikan kondisi rona lingkungan yang berada di lokasi sungai asam, sesuai (SNI 03-7016-2004) dapat dilihat lokasi rona lingkungan (AP2) dan (AP3) yang berada daerah sungai asam, banyak permukiman warga, aktivitas tokoh, perdagangan, perkantoran dan rumah makan. Untuk lebih jelasnya pengambilan titik sampling dapat dilihat pada gambar di bawah

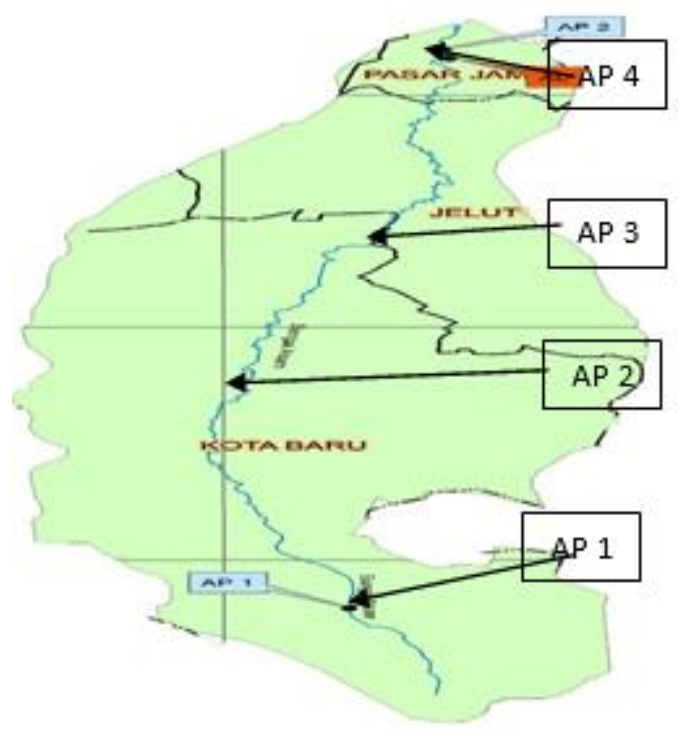

Gambar 1. Lokasi Titik Sampling Sungai Asam

\subsection{Analisis Data}

Setelah pengambilan sampel dilakukan sepanjang titik lokasi yang sudah ditentukan, maka didapatkan konsentrasi 
dari tiap parameter. Analisis parameter dilakukan dengan membuat grafik hubungan konsentrasi tiap parameter dari titik ke titik lainnya (hulu hingga hilir), sehingga dapat dilihat perubahan parameter sepanjang titik lokasi penelitian. Selanjutnya dilakukan perhitungan daya tampung beban pencemaran dengan menggunakan metode neraca massa dan streeter-phelps agar dapat menentukan beban pencemaran dan daya tampung air sungai asam pada titik lokasi.

\section{Hasil dan Pembahasan}

\subsection{Kondisi Hidrolika Sungai Asam}

Data hidrolika didapatkan dari data primer yaitu pengukuran langsung di lapangan. Berikut tabel hasil Analisis Hidrolika Sungai Asam.

Tabel 2 Hasil Analisis Hidrolika Sungai Asam

\begin{tabular}{cccc}
\hline Titik & $\begin{array}{c}\text { Kedalaman } \\
(\mathrm{m})\end{array}$ & $\begin{array}{c}\text { Lebar } \\
(\mathrm{m})\end{array}$ & $\begin{array}{c}\text { Kecepatan } \\
(\mathrm{m} / \text { detik })\end{array}$ \\
\hline AP1 & 0.5 & 1.5 & 6 \\
AP2 & 0.65 & 3 & 4 \\
AP3 & 0.8 & 4 & 4 \\
AP4 & 3.8 & 8.5 & 3 \\
Rata-rata & 1.44 & 4.25 & 4.25 \\
\hline
\end{tabular}

Hasil pada tabel 2 analisis hidrolika Sungai Asam yang diukur secara langsung di lapangan menunjukan kedalaman tertinggi terdapat pada titik AP4 Hilir sebesar $3.8 \mathrm{~m}$, kedalaman dengan lebar sungai sebesar $8.5 \mathrm{~m}$ kedalaman terendah terdapat pada titik AP1 Hulu sebesar $0.5 \mathrm{~m}$, dengan lebar sungai sebesar $1.5 \mathrm{~m}$, dan kecepatan aliran sungai pada titik AP1 Hulu sebesar $6 \mathrm{~m} /$ detik, kecepatan aliran pada titik AP4 Hilir sebesar $3 \mathrm{~m} /$ detik.

Tabel 3 Hasil Analisis Kualitas Air Sungai Asam

\begin{tabular}{|c|c|c|c|c|c|c|c|c|}
\hline \multirow{3}{*}{ Parameter } & \multirow{2}{*}{\multicolumn{4}{|c|}{$\begin{array}{c}\text { Baku Mutu PP 82/2001 } \\
\text { Kelas Air } \\
\end{array}$}} & \multirow{2}{*}{\multicolumn{4}{|c|}{ Hasil Analisa }} \\
\hline & & & & & & & & \\
\hline & $\mathrm{I}$ & II & III & IV & AP1 & AP2 & AP3 & AP4 \\
\hline $\mathrm{pH}$ & $6-9$ & $6-9$ & $6-9$ & $5-9$ & 6.87 & 7.13 & 7.24 & 7.1 \\
\hline DO & 6 & 4 & 3 & 0 & 5.7 & 4,5 & 5.7 & 6.2 \\
\hline COD & 10 & 25 & 50 & 100 & 14 & 19 & 16 & 10 \\
\hline $\mathrm{BOD}_{5}$ & 2 & 3 & 6 & 12 & 1.2 & 1.2 & 1.6 & 1.6 \\
\hline TSS & 50 & 50 & 400 & 400 & 195 & 14 & 14 & 20 \\
\hline
\end{tabular}

\subsection{Kualitas Air Sungai Asam}

Berdasarkan data pada Tabel 3 dengan perbandingan baku mutu air kelas 1 sampai kelas 4 , untuk parameter $\mathrm{pH}$ tertinggi sebesar $7.24 \mathrm{mg} / \mathrm{l}$ pada AP3, parameter $\mathrm{pH}$ terendah sebesar 6.87 pada AP1, dari perbandingan setiap kelas air masih memenuhi baku mutu, untuk parameter DO tertinggi sebesar $6.2 \mathrm{mg} / \mathrm{l}$ pada AP4, parameter DO terendah sebesar $4.5 \mathrm{mg} / \mathrm{l}$ pada AP2, perbandingan kelas air yang memenuhi baku mutu hanya pada kelas I, untuk parameter COD tertinggi sebesar $19 \mathrm{mg} / \mathrm{l}$ pada AP2, parameter COD terendah sebesar $10 \mathrm{mg} / \mathrm{l}$ pada AP4, perbandingan kelas air yang melebihi baku hanya pada kelas I, parameter $\mathrm{BOD}_{5}$ tertinggi sebesar $1.6 \mathrm{mg} / \mathrm{l}$, $\mathrm{BOD}_{5}$ terendah sebesar $1.2 \mathrm{mg} / \mathrm{l}$, perbandingan setiap kelas air masih dibawah baku mutu, dan untuk parameter TSS tertinggi sebesar $195 \mathrm{mg} / \mathrm{l}$, TSS terendah sebesar $14 \mathrm{mg} / \mathrm{l}$, perbandingan kelas air yang memenuhi baku mutu yaitu pada kelas III dan kelas IV.

3.3 Hasil Analisis Daya Tampung Beban Pencemaran Air sungai Menggunakan Metode Neraca massa
Perhitungan daya tampung beban pencemaran neraca massa digunakan untuk menetukan konsentrasi pada titik pecampuran air limbah pada setiap titik lokasi yang di uji yaitu di tentukan pada pertitik lokasi AP dengan satu titik lokasi menghasilkan beban pencemaran pada AP1, AP2, AP3 dan AP4. Sedangkan pencampuran pada semua titik lokasi yang di uji mengasilkan daya tampung beban pencemaran sungai asam dari hulu sampai hilir. Berikut adalah data air limbah dan air permukaan, menentukan titik pencampuran dengan metode neraca massa. Ditunjukan pada Tabel 4 sebagai berikut :

Tabel 4 Hasil data debit, kualitas air limbah dan air Sungai

\begin{tabular}{cccccc}
\multicolumn{7}{c}{ Asam } \\
\hline \multirow{2}{*}{ Titik } & $\begin{array}{c}\text { Debit } \\
\mathrm{m}^{3} / \text { detik }\end{array}$ & $\begin{array}{c}\text { COD } \\
\mathrm{mg} / \mathrm{L}\end{array}$ & $\begin{array}{c}\text { TSS } \\
\mathrm{mg} / \mathrm{L}\end{array}$ & $\begin{array}{c}\text { BOD } \\
\mathrm{mg} / \mathrm{L}\end{array}$ & $\begin{array}{c}\mathrm{pH} \\
\mathrm{mg} / \mathrm{L}\end{array}$ \\
\hline AL & 0.00018 & 100 & 30 & 30 & 6.30 \\
AP1 & 0.12 & 14 & 195 & 1.2 & 6.87 \\
AP2 & 0.48 & 19 & 14 & 1.2 & 7.13 \\
AP3 & 0.80 & 16 & 14 & 1.6 & 7.24 \\
AP4 & 10.7 & 20 & 20 & 1.6 & 7.10 \\
\hline
\end{tabular}

\subsection{Hasil Analisis Pencampuran Per-titik Lokasi AP (Air Permukaan)}

Beban pencemaran suatu parameter pencemaran yang terkandung dalam sejumlah air atau limbah dengan hasil analisis dihitung pada satu titik lokasi pencampuran (AP Mixing) dengan tujuan untuk mengetahui beban yang tercemar pada (Empat) titik lokasi yang berbeda (AP1),(AP2),(AP3), dan (AP4). Berikut data hasil perhitungan pencampuran (Mixing) per titik lokasi (AP) pada Tabel 5.

Tabel 5 Data hasil perhitungan pencampuran pada titik AP (Air permukaan)

\begin{tabular}{cccccc}
\hline Aliran & $\begin{array}{c}\text { Debit } \\
\mathrm{m}^{3} / \mathrm{dtk}\end{array}$ & $\begin{array}{c}\text { COD } \\
\mathrm{mg} / \mathrm{L}\end{array}$ & $\begin{array}{c}\mathrm{TSS} \\
\mathrm{mg} / \mathrm{L}\end{array}$ & $\begin{array}{c}\mathrm{BOD} \\
\mathrm{mg} / \mathrm{L}\end{array}$ & $\begin{array}{c}\mathrm{pH} \\
\mathrm{mg} / \mathrm{L}\end{array}$ \\
\hline AP1 & 0.12 & 14.00 & 194.71 & 1.20 & 6.87 \\
$\mathrm{AP} 2$ & 0.48 & 19.01 & 14.00 & 1.20 & 7.13 \\
AP3 & 0.80 & 16.01 & 14.00 & 1.61 & 7.24 \\
AP4 & 10.70 & 20.02 & 20.01 & 1.61 & 7.10 \\
BML & - & 25 & 50 & 3 & $6-9$ \\
\hline
\end{tabular}

\subsection{Data Hasil Analisis Pencampuran Pada Seluruh Titik} Lokasi AP (Air Permukaan)

Hasil analisis dihitung pada semua titik lokasi pencampuran AP1 (Hulu) sampai AP4 (Hilir) dengan air limbah domestik. Maka perhitungan menghasilkan beban pencemaran dari Hulu Sampai Hilir sungai asam. Berikut data hasil perhitungan pencampuran seluruh lokasi (AP) pada Tabel 6.

Tabel 6 Data hasil analisis perhitungan seluruh titik (AP)

\begin{tabular}{cccccc}
\hline \multirow{2}{*}{ Aliran } & $\begin{array}{c}\text { Debit } \\
\mathrm{m}^{3} / \mathrm{dtk}\end{array}$ & $\begin{array}{c}\mathrm{COD} \\
\mathrm{mg} / \mathrm{L}\end{array}$ & $\begin{array}{c}\mathrm{TSS} \\
\mathrm{mg} / \mathrm{L}\end{array}$ & $\begin{array}{c}\mathrm{BOD} \\
\mathrm{mg} / \mathrm{L}\end{array}$ & $\begin{array}{c}\mathrm{pH} \\
\mathrm{mg} / \mathrm{L}\end{array}$ \\
\hline AP & 0.12 & 27.22 & 23.08 & 4.01 & 7.37 \\
$\mathrm{BML}$ & - & 25 & 50 & 3 & $6-9$ \\
\hline
\end{tabular}

Dari data hasil analisis perhitungan pencampuran (mixing) neraca massa konsentrasi yang melebihi baku mutu menunjukkan bahwa pada aliran sungai (AP1 Hulu) sampai (AP4 Hilir) konsentrasi COD melebihi nilai baku mutu sebesar $27.22 \mathrm{mg} / \mathrm{L}$ dimana baku mutunya adalah $25 \mathrm{mg} / \mathrm{l}$. Hal ini disebabkan lokasi aliran Sungai Asam banyak melintasi 
permukiman rumah warga. Konsentrasi BOD juga melebihi baku mutu sebesar $4.01 \mathrm{mg} / \mathrm{l}$ dimana baku mutunya adalah 3 $\mathrm{mg} / \mathrm{l}$.

\subsection{Hasil Perhitungan Daya Tampung Beban Maksimum Pertitik Lokasi (AP)}

Daya tampung beban pencemaran kemampuan air pada suatu sumber air untuk menerima masukan beban pencemar tanpa mengakibatkan air tersebut menjadi tercemar. Berikut adalah Hasil perhitungan daya tampung beban maksimum pada pertitik lokasi dengan metode neraca massa pada titik pencampuran ditunjukan dalam Tabel 7 sebagai berikut :

Dari data hasil analisis perhitungan neraca massa konsentrasi pencampuran pertitik lokasi AP yang melebihi baku mutu air kelas II sesuai PP RI Nomor 82 Tahun 2001 menunjukan bahwa pada AP1 parameter COD, BOD, $\mathrm{pH}$, masih dibawah baku mutu sedangkan nilai TSS sudah melebihi baku mutu sebesar $194.71 \mathrm{mg} / \mathrm{L}$, sebab hasil data primer yang diuji nilai TSS sudah melebihi baku mutu. Sedangkan konsentrasi pada AP2 , AP3 dan AP4 untuk parameter COD, BOD, TSS, dan $\mathrm{pH}$ rata-rata dibawah baku mutu. sedangkan konsentrasi $\mathrm{pH}$, TSS masih dibawah baku mutu.

Tabel 7. Daya Tampung Beban maksimum Metode Neraca Massa

\begin{tabular}{ccccc}
\hline \multirow{2}{*}{ Titik } & \multicolumn{4}{c}{ Konsentrasi yang dapat ditampung sungai } \\
\cline { 2 - 5 } & COD & TSS & BOD & pH \\
\hline AP1 & 57.516 & -110.129 & 19.257 & $2,72-12,34$ \\
AP2 & 21.641 & 42.758 & 7.694 & $2,20-11,14$ \\
AP3 & 37.397 & 71.220 & 12.643 & $2,34-10,14$ \\
AP4 & 47.625 & 59.503 & 16.906 & $2,01-12,7$ \\
BML & 100 & 30 & 30 & $6-9$ \\
\hline
\end{tabular}

Dari hasil analisis perhitungan daya tampung beban maksimum dengan metode neraca massa konsentrasi yang melebihi baku mutu air limbah domestik sesuai PP RI Nomor 68 Tahun 2016 menunjukan bahwa pada AP1 (Hulu) Parameter COD, BOD, pH, masih dibawah baku mutu sedangkan nilai TSS sudah tidak dapat ditampung sungai sebesar - $110.129 \mathrm{mg} / \mathrm{L}$. Lokasi pada AP2 (Tengah) untuk parameter COD dan $\mathrm{pH}$ masih dibawah baku mutu sedangkan yang melebihi baku mutu yaitu TSS sebesar $42.758 \mathrm{mg} / \mathrm{L}$ dan BOD sebesar $76.941 \mathrm{mg} / \mathrm{L}$. Pada lokasi AP3 (Tengah) dan AP4 (Hilir) untuk parameter COD, BOD, dan $\mathrm{pH}$ rata-rata masih dibawah baku mutu air limbah domestik, pada TSS AP3 (Tengah) dan AP4 (Hilir) melebihi baku mutu sebesar 71.220 $\mathrm{mg} / \mathrm{L}$ dan $59.503 \mathrm{mg} / \mathrm{L}$.

\subsection{Analisis Perhitungan Daya Tampung Beban Pencemaran Menggunakan Metode Streeter-Phelps}

Analisis daya tampung beban pencemaran menggunakan metode steeter-phelps digunakan untuk menganalisis daya tampung beban pencemaran air yang didasarkan pada perubahan oksigen terlarut DO di dalam air. Perubahan DO. ditentukan oleh dua fenomena yaitu proses pengurangan DO (deoksigenasi) akibat aktivitas bakteri dalam mendegradasi bahan organik dalam air dan peningkatan DO yang diakibatkan oleh trubulensi yang terjadi pada aliran sungai sehingga terjadi proses rearasi.
Tabel 8 Hasil perhitungan laju deoksigenasi dan reaerasi

\begin{tabular}{ccc}
\hline Aliran & $\mathrm{Kd}(\mathrm{L} / \mathrm{hari})$ & $\mathrm{Kr}(/ \mathrm{L} / \mathrm{hari})$ \\
\hline AP1 Hulu & 0.573 & 9.596 \\
AP2 Tengah & 0.696 & 4.127 \\
AP3 Tengah & 0.670 & 2.918 \\
AP4 Hilir & 0.806 & 0.162 \\
Rata-rata & 0,696 & 4.200 \\
\hline
\end{tabular}

Laju deoksigenasi menunjukan kecepatan penurunan oksigen yang digunakan mikroganisme di dalam air untuk mengurangin bahan organik. Laju deoksigenasi tertinggi terdapat pada titik AP4 Hilir sebesar 0.806 L/hari, laju deoksigenasi tinggi menunjukan bahwa proses dekomposisi bahan organik berlangsung cepat. Laju deoksigenasi terendah pada titik AP1 Hulu yaitu sebesar 0,573 L/hari.

Laju reaerasi menunjukan kecepatan peningkatan oksigen didalam air. Laju reaerasi berbanding terbalik dengan laju deoksigenisasi dimana saat laju reareasi tinggi maka laju deoksigenisasi akan rendah. Laju reaerasi tertinggi terdapat pada titik AP1 Hulu sebesar 9.596 L/hari dikarenakan nilai kedalaman pada titik AP1 Hulu sebesar $0.5 \mathrm{~m}$ dan $0.6 \mathrm{~m} /$ detik. Sungai dangkal dan kecepatan aliran tinggi menyebabkan nilai konstanta reaerasi juga tinggi (Astono 2010).

\subsection{DO kritis dan waktu Kritis}

Hasil perhitungan DO kritis dan waktu Kritis, disajikan pada Tabel 8 sebagai berikut :

Tabel 8 Data hasil perhitungan DO kritis dan waktu kritis

\begin{tabular}{cccc} 
Titik & $\begin{array}{c}\text { Panjang } \\
(\mathrm{Km})\end{array}$ & $\begin{array}{c}\text { Waktu kritis } \\
\text { (hari) }\end{array}$ & $\begin{array}{c}\text { Oksigen kritis } \\
(\mathrm{mg} / \mathrm{l})\end{array}$ \\
\hline AP1 & 1.14 & $-0,559$ & 5.690 \\
AP2 & 3.10 & $-0,890$ & 5.801 \\
AP3 & 3.10 & $-1,328$ & 6.124 \\
AP4 & 3.34 & $-2,691$ & 6.910 \\
\hline
\end{tabular}

pada konsentrasi limbah yang masuk ke dalam sungai asam di setiap titik lokasi yang berbeda. Proses purifikasi bergantung pada laju reaerasi dan deoksigenasi yang ditunjukkan dengan kurva penurunan oksigen. Hubungan antara oksigen kritis dan waktu kritis disajikan pada gambar 1.

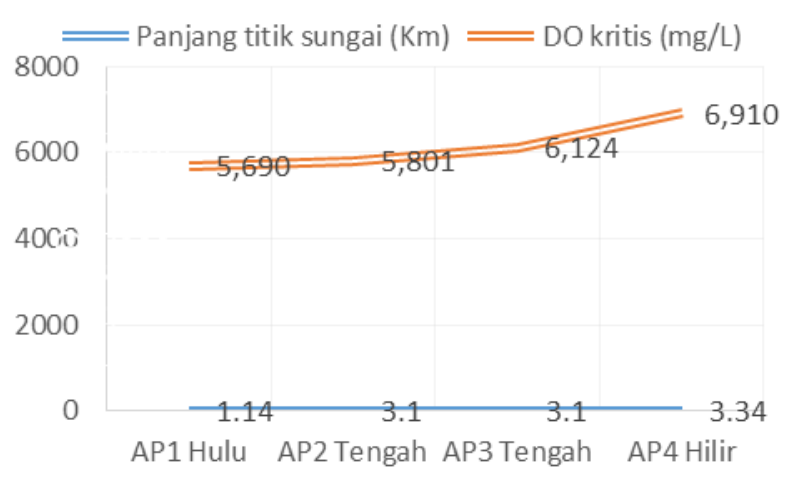

Gambar 2. waktu kritis bernilai negative

Menunjukan bahwa tidak terdapat waktu kritis pada sungai karena nilai DO kritis dari AP1 hulu sampai AP4 Hilir mengalamin peningkatan sebesar 5,691 mg/l. Hal ini berarti potensi limbah yang ada di sekitar sungai tidak sampai mencemari air sungai yang mempengaruhi turbulensi. dari data hidrolik pada sungai asam pada tabel 4.1 debit air sungai 
asam dari titik AP1 hulu sampai titik AP4 hilir debit air semangkin bertambah yaitu debit sebesar $0.12 \mathrm{~m}^{3} /$ detik sampai $10.7 \mathrm{~m}^{3} /$ detik.

\section{Kesimpulan}

Berdasarkan hasil perhitungan daya tampung beban pencemaran sungai menggunakan metode neraca massa pada parameter, pH, TSS, BOD dan COD. Sungai Asam yang tidak dapat menampung beban pencemaran terdapat pada parameter TSS sebesar -110.129,12 mg/l dengan baku mutu $30 \mathrm{mg} / \mathrm{l}$ sesuai Kemen-LHK Nomor P.68 Tahun 2016 tentang baku mutu limbah domestik, Sedangkan untuk parameter $\mathrm{pH}, \mathrm{BOD}$, dan COD masih dibawah baku mutu limbah domestik.

Hasil perhitungan daya tampung beban pencemaran menggunakan metode streeter-phelps Menunjukan bahwa pada 4 (empat) titik sampling konsentrasi BOD masih dapat menampung beban pencemaran disungai yang tidak melebihi baku mutu sesuai Kemen-LHK Nomor P.68 Tahun 2016 tentang limbah domestik. Karena pengaruh dari konsentrasi DO pada AP1 Hulu sampai AP4 Hilir masih tersedia DO dalam Jumlah yang cukup.

\section{Daftar Pustaka}

Alfan Kurnianto (2014). Kualitas Air Sungai Kalimas Kota Surabaya Menggunkan Metode Indeks Pencemaran. http://digilib.uinsby.ac.id/id/eprint (diakses 13 Agustus 2019)

Arbie, R. R., W. D. Nugraha, dan Sudarno. 2015. Studi Kemampuan Self Purification pada Sungai Progo Ditinjau dari Parameter Organik DO dan BOD (Point Source : Limbah Sentra Tahu Desa Tuksono,Provinsi D.I.Yogyakarta). Jurnal Teknik Lingkungan.

Agus Darmawan (2018). Daya Tampung Beban Pencemaran Sungai Bedadung menggunakan metode Streeter Phelps (Studi Kasus di Desa Tamansari dan Desa Lojejer Kecamatan Wuluhan Kabupaten Jember).

Afresa Amanda, Rony Riduan, Chairul Abdi (2020). Analisis Daya Tampung Sungai Terhadap Beban Pencemar Organik.Vol 3(2)tahun 2020

Adrian Rizali Saputra (2016). Strategi Pengendalian Kualitas Air Sungai Kuin Banjarmasin Berdasarkan Daya Tampung Beban Pencemar.

Bambang Rahadi widiatmono, Komang Della Pavita, Liliya dewi (2017) Studi Penentuan Daya Tampung Beban Pencemaran Kali Surabaya dengan menggunakan Metode Neraca Massa. Diakses 3 desember 2017.

Dinas Lingkungan Hidup Kota Jambi (2020) Data Kualitas Air sungai Asam Kota Jambi Bagian Hilir Asam dan Bagian Hulu Asam.

Dinas Lingkungan Hidup Kota Jambi (2020) Data Lebar penampang Basah, Kedalaman Air, Laju Air dan Debit air sungai Asam Kota Jambi, bagian Hulu dan Hilir.

Effendi, Hefni. 2003. Telaah Kualitas Air Bagi Pengelolaan Sumber Daya dan Lingkungan Perairan. Kanisius. Yogyakarta.

Fernando Hero Alyandri, Noveri Mulya, Rika Reskika Sari, Suci Ika Nofrilianti, Fadhilla Oktari, Eko Satria Permana, Fungky Novendri (2019). Analisis Kualitas Air dan Strategi Pengendalian Pencemaran Air Sungai Tiga Titik di Kecamatan Kota Padang
Ginanjar Trilaksono, Dr.Ing.Sudarno,S.T,MSc, Ir.Dwi Siwi Handayani, MSi (2013). Studi Penetuan Daya Tampung Beban Pencemaran Air Sungai Melalui Pendekatan Software QUAL2E dan Metode Neraca Massa (Studi Kasus : Sungai Garang, Jawa Tengah).

Hendriarianti, E. dan N. Karnaningroem. 2015. Deoxygenation Rate of Carbon in Upstream Brantas River in the City of Malang. Journal of Applied Environtmental and Biological Science, 5(12): 36 - 41.

Keputusan Menteri Negara Lingkungan Hidup Nomor 110 Tahun 2003. Pedoman Penetapan Daya Tampung Beban Pencemaran Air pada Sumber Air. 27 Juni 2003. Menteri Negara Lingkungan Hidup. Jakarta: Deputi 1 MENLH Bidang Kebijakan dan Kelembagaan Lingkungan Hidup.

Nelly Marlina, Kasam, dan Any Juliani (2015). Evaluasi Daya Tampung Terhadap Beban Pencemar Menggunakan Model Kualitas Air (Studi Kasus: Sungai Winongo). Vol 4 (2) 78-86.

PT Indofood CBP Sukses Makmur Tbk (2020). Dokumen Kajian Teknis Pembuangan Air Limbah ke Permukiman Warga Mengunakan Metode Neraca Massa dan Streeter-Phelps. (Industri Mie Instan ) Kota Jambi.

PT Hok Tong (2020). Dokumen Kajian Teknis Pembuangan Air Limbah Produksi

dan Domestik ke Air Permukaan Mengunakan Metode Neraca Massa. PT Hok Tong Kota Jambi.

Peraturan Daerah Kota Jambi Nomor 09 Tahun 2013. Tentang Rencana Tata Ruang Wilayah Kota Jambi Tahun 20132033.

Peraturan Pemerintah Republik Indonesia Nomor 82 Tahun 2001. Pengelolaan Kualitas air dan Pengendalian Pencemaran Air. 14 Desember 2001. Jakarta: Kementerian Sekretariat Negara RI.

Peraturan Menteri Lingkungan Hidup dan Kehutanan Republik Indonesia Nomor P.68/MENLHKSETJEN/2016. Tentang Baku Mutu Air Limbah Domestik. www.peraturan.go.id

Peraturan Undang-Undang Republik Indonesia, Nomor 17 Tahun,2019. Tentang Sumber Daya Air. 15 Oktober 2019. Jakarta : Kementerian Sekretariat Negara RI

Suryo Ari W, Winardi Dwi Nugraha, Endro Sutrisno (2014). Analisis Kualitas Air Sungai Bringin Kota Semarang dengan Metode NSF - IKA (Studi Kasus Sungai Bringin Pada Tanggal 10 Juli 2014 ).

Sri Wahyuningsih, Elida Novita, Sayyidatul Nahda Afifah (2020). Daya Tampung Beban Pencemaran Sungai Sumber Telak Kabupaten Jember Menggunakan Metode,Streeter-Phelps. Vol 39 (2) 87-96

Standar Nasional Indonesia Nomor 6989-57. 2008. Metode Pengambilan Contoh Air Permukaan. Jakarta: Badan Standarisasi Nasional.

Standar Nasional Indonesia Nomor 8066. 2015. Tata Cara Pengukuran Debit Aliran Sungai dan Saluran Terbuka Menggunakan Alat Ukur Arus dan Pelampung. Jakarta: Badan Standarisasi Nasional.

Taufik Dani, Suripin, Sudarno (2015). Analisis Daya Tampung Beban Cemar di DAS Bengawan Solo Segmen Kota Surakarta dan Kabupaten Karanganyar dengan Model QUAL2KW. Vol.13(2),92-102 